\section{TEXT PRIZE}

The deadline for the 1999 ASA Text Prize has been extended, and the award will be given out in November 2000 during the next ASA Annual Meeting. The parameters of the prize remain the same. That is, only those books published in 1997 and 1998 are eligible this year. In 2001, books published in 1999 and 2000 will be eligible.

The ASA Text Prize recognizes the best critical edition or translation into English of primary source materials on Africa published during the preceding two years. Texts dealing with the history, literature and other aspects of the cultures of Africa, whether in African or European languages, whether the text was being published for the first time or in a new edition, are eligible for consideration. The evaluation is based on the importance of the text, the presentation of the text and the critical apparatus, and the utility of the work as a whole for scholars and teachers of Africa Works edited by a single individual or jointly edited by more than one person are eligible, but not anthologies with separate contributions by different authors. The minimum length is 10,000 words, excluding apparatus. Contact the ASA Office for submission guidelines and new deadline.

\section{CHILDREN'S BOOK AWARD}

The Outreach Council of the ASA sponsors the Children's Book Award, offered annually to the best book published for K12 children by a US trade publisher. The award consists of a plaque and is presented at the ASA Awards Ceremony to the author and illustrator of the winning book. The initial Children's Book Award was presented in 1992. The award is administered through the Outreach Council. For information about the 2000 award, contact the Children's Book Award Committee Chair, Brenda Randolph, via email brendar@umd5.umd.edu.

\section{ANNOUNCEMENTS}

\section{Writers Wanted}

Editorial work has begun on the fourth edition of the International Dictionary of Films and Filmmakers, a four-volume reference guide to films, directors, actors and actresses, and writers and production artists. The set currently features over $2,(0)(0)$ entries on the most important figures and films in the world of international cinema. The entries contain biographical information, filmographies, bibliographies, and a critical essay. Subject matter experts are needed to contribute signed entries for this new edition, as well as to update previous entries. Entries will be approximately 1,000 words in length and will also include biographical and bibliographical information. If you are interested in contributing to this publication, please send a brief letter or email describing your qualifications and evidence of your ability to analyze the field of international cinema. For more information please contact: Tom and Sara Pendergast, Editors, International Dictionary of Films and Filmmakers Full Circle Editorial, Inc., 428 Avenue J., Snohomish, WA 98290; Tel.: (360) 568-2049; Fax: (815) 371-2934; Email: fullc@gte.net.

\section{Modern East African Art Exhibit}

The Art Center announces an exhibit of East African fine art in San Francisco. While traditional art forms such as masks and sculpture have been collected for centuries, since the 1930s world-class works of fine art have developed among members of East Africa's Ugandan School. Collected throughout Europe for decades, this exhibit marks the arrival of East African modern painting in the Bay Area. Important original works by leading Ugandan artists, James Kitamirike and David Kibuuka, among others, are exhibited. The exhibit runs through August 31, 2000). For viewing hours, contact: Alexander Calder,
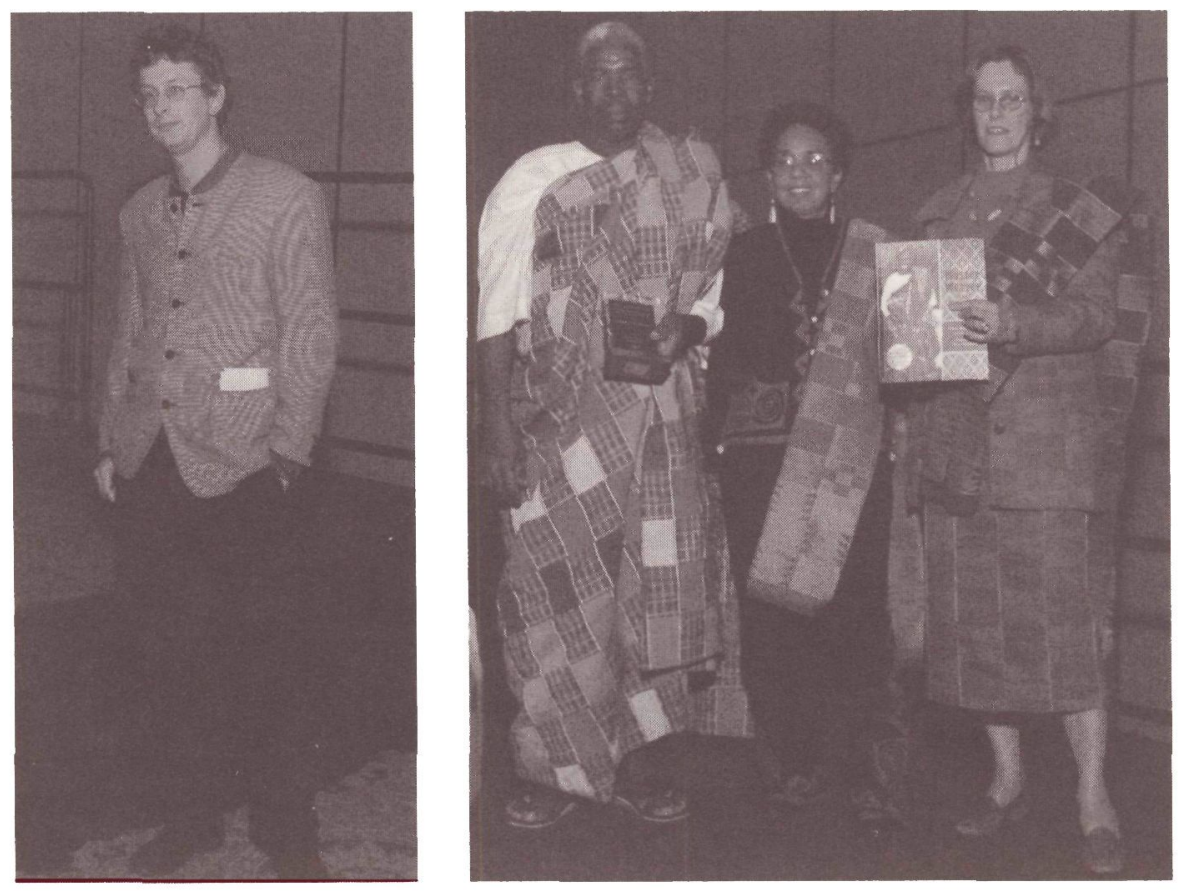

Pictured from left to right: Peter Uvin stands for pose after receiving the 1999 Herskovits Award at the 42nd Annual Meeting in Philadephia. Two winners of the 1999 Childrens's Book Award, Gilbert "Bobbo" Ahiagble (left) and Louise Meyer (right), authors of Master of Weaving from Ghana (Open Hand Publishing, 1998), stand with Brenda Randolph (center), Chair of the Children's Book Award Committee. 
Curator, The Art Room, 1072 Geneva Ave., San Francisco, CA 94112; Tel.: (415) 333 9363; Email: gadart@aol.com.

\section{Zanzibar International Film Festival}

The Zanzibar International Film Festival (ZIFF) "Festival of the Dhow Countries" is June 30 to July 9, 2000. Submissions are being invited for films/videos by producers and/or directors from both the Dhow Countries (Africa, the Indian Ocean Islands, Gulf States, Iran, Pakistan, and India) and the international community. These may be submitted in either competition or non-competition categories. The deadline for Entry Forms to be returned to ZIFF office in Zanzibar is May 1, 2000. Information and entry forms are available on the website. For further information, please contact: Zanzibar International Film Festival, PO Box 3032, Zanzibar, Tanzania; Tel: 255-54-233135; Email: ziff@zanzibar.org; Website: www.zanzibar.org/ziff.

\section{AWARDS \& FELLOWSHIPS}

\section{Postdoctoral Fellow}

The Center for Culture and History of Black Diaspora at DePaul University invites applications for a postdoctoral fellow position for the academic year commencing Fall 2000. Applicants from all disciplines with scholarly interests in race/ ethnicity, gender, class, nationality, language and migration/ displacement are encouraged to apply. The acceptance of the postdoctoral fellow position carries with it the commitment to contributing toward program development of the Center, making a contribution to the research activities of the Center, as well as teaching four courses during the course of a threequarter academic year. The stipend for this position is $\$ 36,000$. The fellow will be provided with an office and have the use of a computer. Previous teaching experience, inclusive of teaching assistantships, is highly desirable. Applicants should submit a letter of application consisting of a single-page statement of proposed activity that describes how the applicant expects the award to enhance their professional advancement. Applicants are further required to submit a curriculum vita, two letters of reference, as well as a course syllabus. Complete applications must be received by April 3, 2000 to assure full consideration. Application materials should be submitted to: Dr. Sandra Jackson, Director Center for Culture and History of Black Diaspora, 2320 N. Kenmore Ave., Chicago, IL 60614-3298; Tel:(773) 325 7536;Fax: (773) 325 7452; Email: fdemissi@condor.depaul.edu;

Website: www.depaul.edu/ demissi.

\section{PAPER CALENDAR}

\section{Women of African Descent}

The Women's Studies Program at Southern Connecticut State University would like to announce the Call for Sessions for its tenth annual conference, "Women of African Descent: Reaching Out Across the Diaspora" which will be held October 6-7, 2000. Submissions for papers (500 word proposal) and panels (750 word proposal) on any aspect on women of African descent are invited. Possible session formats include, but are not limited to, roundtable discussions, workshops, paper presentations, performances, slide/video shows, poster sessions, works-in-progress, and exhibits. The submission deadline is June 2, 2000. For more information, please contact: Women's Studies Program, MO B007, Southern Connecticut State University, 501 Crescent St., New Haven, CT 06515-1355; Tel.: (203)392-6133; Fax: 203-392-6723; Email: womenstudies@scsu.ctstateu.edu; Website:scsu.ctstateu.edu/ womenstudies/ wmst.html

\section{GhaCLAD Conference}

The Ghana Computer Literacy and Dis-
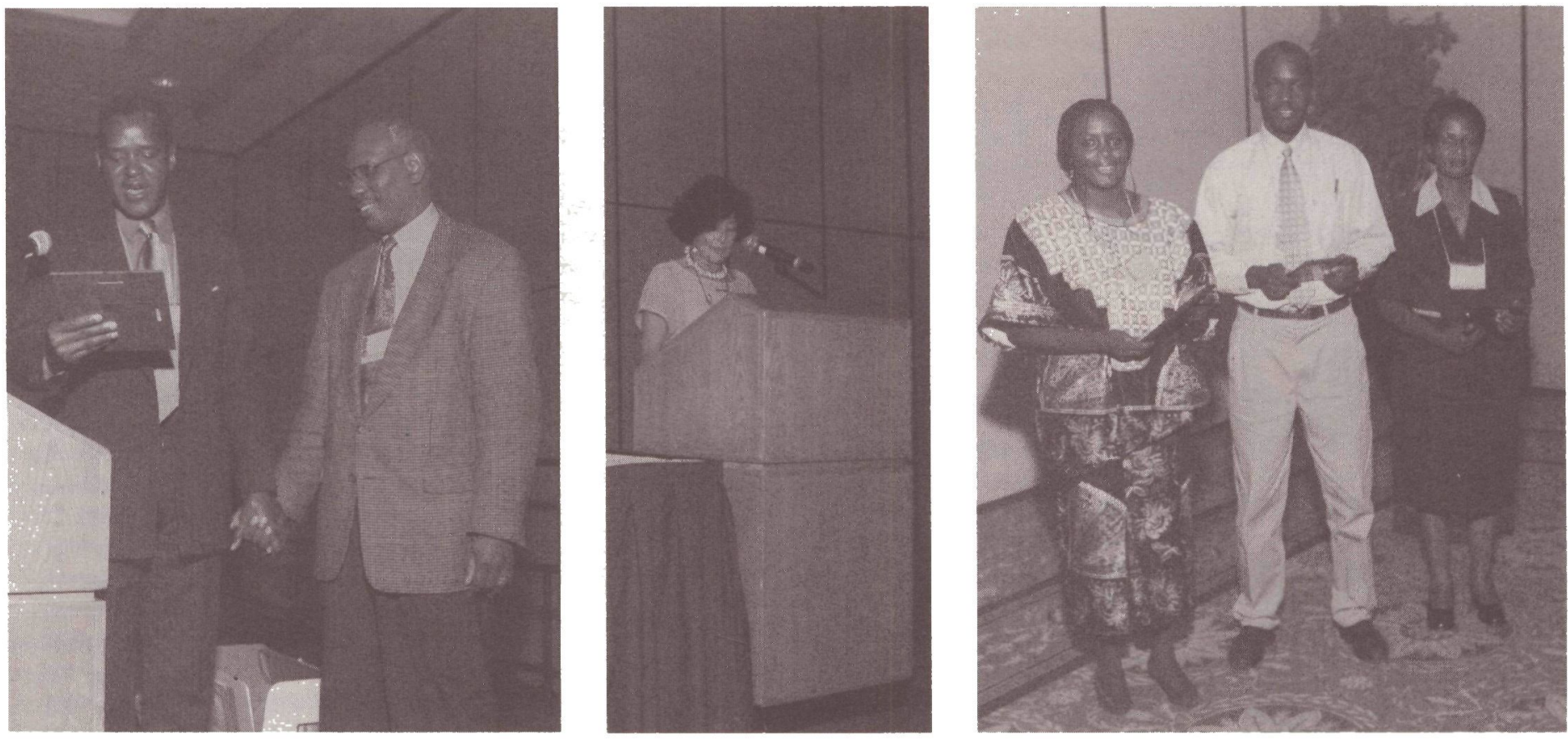

Pictured from left to right: ASA President, Lansine Kaba, presents Boubacar Barry with a plaque for serving as the Abiola Lecturer at the 42nd Annual Meeting in Philadelphia. Catherine Coquery-Vidrovitch accepts the Distinguished Aficanist Award A few International Visitors Award winners pose with their awards (complete list of the 1999 International Visitor's Award winners, p. 19). 


\section{The Arts Council of the African Studies Association (ACASA) presents \\ 12th International Triennial Symposium on African Art \\ Transitions, Passages, and Confluences \\ April 25-29 2001 \\ Marriott Frenchman's Reef \\ St. Thomas, Virgin Islands \\ Submit paper proposals to: For hotel reservations: \\ Eli Bentor, Program Committee Chair Marriott Frenchman's Reef \\ Appalachian State University PO Box 7100 \\ Department of Art St. Thomas, USVI $00801 * 0100$ \\ Boone, NC 28608 Fax: 340-715-6191}

Tel: 828-262-2579 Fax: 828-262-6756

Email: bentore@appstate.edu

Proposal deadline: March 31, 2000

The symposium is hosted by the University of the Virgin Islands.

The conference will coincide with carnival, and carnival events will be built into the schedule.

tance Education Conference (GhaCLAD) conference is July $26-29,2000$, at the LaPalm Royal Beach Hotel. The main theme for GhaCLAD 2000 is "Moving Toward an African Educational \& Health Information Highway: Visions, Opportunities and Challenges." All of our sessions will be focused on specific proposals for moving into action. Please send one page abstracts via email to callforpapers@ghaclad.org. For information, contact: Tel.: (312) 996 8508; Email: ghaclad@ghaclad.org; Website: www.ghaclad.org.

\section{MEETING \\ CALENDAR}

\section{Southeast Regional Seminar in African Studies}

The Southeast Regional Seminar in African Studies (SERSAS) is pleased to announce its Spring 2000 conference, to be hosted by Western Carolina University April 14 - 15. SERSAS takes great pride in providing time for in-depth discussion of papers in a friendly and relaxed atmosphere and encourages faculty to take advantage of SERSAS' famed collegiality by bringing advanced undergraduates and new graduate students as a means of introducing them to the workings of an academic conference. For more information, contact: Email: SERSAS@hotmail.com; Website: www.ecu.edu/africansersashomepage.html.

\section{MAAAS Conference}

The Mid-America Alliance for African Studies (MAAAS) will host a conference at Kansas State University in Manhattan, KS, September 30, 2000. The general theme is "Africa and Its Environment." The registration deadline is September 7. For more information: Claire L. Dehon, Department of Modern Languages, Eisenhower Hall, Kansas State University, Manhattan, KS 66506; Tel: (785) 532 1929; Fax: (785) 532 7004; Email: dehoncl@ksu.edu.

\section{Taking Stock in African Studies}

The Canadian Association of African Studies (CAAS) announces its 2000 conference, "Taking Stock in African Studies: Agendas for Teaching and Research Beyond 2000." The conference is May 27-30, 2000, at the University of Alberta, Edmonton. Again this year CAAS will be meeting with the Congress of the Humanities and Social Sciences. For information, please contact: Congress Secretariat, 415-151 Slater St., Ottawa, Ontario K1P5H3; Tel: (613) 238-6112. Fax: (613) 236-4853; Email: congress@hssfc.ca.

\section{Graduate Student Workshop}

The Canadian Council of Learned Societies is pleased to announce a training session for graduate students that will be held in conjunction with the Canadian Association for African Studies annual conference May 27-30, 2000, at the University of Alberta, Edmonton. Students interested in participating should apply to: Ms Loy Denis, Canadian Council of Area Studies Learned Societies, c/o CETASE, University of Montreal; C.P. 6128 Succ. CentreVille, Montreal, Quebec. Н3С 3J7; Tel. (514) 343 6569; Fax: (514) 3437716.

\section{Zimbabwe Intemational Book Fair}

The 2000 Zimbabwe International Book Fair (ZIBF) is July 28-August 5, in Harare. The theme is "Celebrating African Books." This year the fair focusess on Ghana, one of Africa's most enterprising publishing and book-selling nations. The program includes a celebration of the first award of the Caine Prize for African Writing and a training workshop on scholarly publishing in Africa. For more information, please contact: ZIBF (UK) Ltd., David Brine, Marketing Manager, PO Box 21303, London WC2E 8PH; Tel: 44 (0)2() 78368501; Fax: 44 (0)20 78368501; Email: zibf.kingstreet@dial.pipex.com; Website: www.zibf.org. 


\section{Chaired Professorshipp In African Stun olies}

Smith College is seeking an eminent Africanist scholar to become the Gwendolen Carter Professor of African Studies, a chaired full professorship with tenure. The chair has been established to honor Gwendolen Carter who taught Government at Smith for over 20 years.

The field of the appointee is open, but outstanding candidates in history, economics, english, philosophy, religion and sociology are especially encouraged to apply, as are those with an interest in African-American and Diaspora studies.

Candidates should send a CV, A letter describing their work, and the names of references to: Search Committee, Carter Professorship, College Hall 27, Smith College, Northampton, MA 01063. The search committee has begun reviewing applications and will continue the process until the position is filled. Smith College is an equal opportunity employer encouraging excellence through diversity.

\section{Smith College}

Visit us at www.smith.edu

\section{RECENT}

\section{DOCTORAL DISSERTATIONS}

\section{Compiled by \\ Joseph J. Lauer and Mary Mwiandi Michigan State University}

The theses listed below were reported in Dissertation Abstracts International (DAI), vol. 60, no. 4-5 or in Index to Theses, with Abstracts, Accepted for Higher Degrees by the Universities of Great Britain and Ireland (Aslib), v. 48, no. 3-4. Each citation ends with the order number, if any. American and Canadian theses are usually available from University Microfilms International (PO Box 1346, Ann Arbor, MI 48106-1346). UK theses with BL are available from the British Thesis Unit, British Library Document Supply Centre, Boston Spa, Wetherby, LS23 7BG, UK. (The Center for Research Libraries purchases foreign dissertations upon demand.) See DAI or Aslib for abstracts and other details.

This is the 45th quarterly supplement to American and Canadian Doctoral Dissertations and Master's Theses on Africa, 1974-1987 (Atlanta: ASA/Crossroads Press, 1989).

\section{Agriculture}

Darfaoui, El Mostafa. Livestock watering practices in the Moroccan pre-Sahara: their effects on water and nutrient metabolism of sheep in different body conditions. Ph.D., Utah State U., 1998. 9926520.

Dadi, L. Adoption and diffusion of agricultural technologies: case of East and West Shewa zones, Ethiopia. Ph.D., Manchester (U.K.), 1998.

Kangire, A. Fusarium wilt (Panama disease) of exotic bananas and wilt of East African Highland bananas (Musa, AAA-EA) in Uganda. Ph.D., Reading (U.K.), 1998. BL.

Kluvitse, Yvonne Maanu. Nutritional, physicochemical and sensory evaluation of extrusion-cooked cereal/legume weaning formulations [Ghana]. Ph.D., U. of Georgia, 1999. 9928949.

Lusigi, A. M. Productivity in African agriculture: measuring and explaining growth. Ph.D., Reading (U.K.), 1998. BL.

Murithi, F. M. Economic evaluation of the role of livestock in mixed smallholder farms of the Central Highlands of Kenya. I'h.D., Reading (U.K.), 1998. BL.

Onyebuchi, C. C. Land use change in Makurdi area of Benue State, Nigeria: assess- ment by remote sensing, GIS and rapid rural appraisal (RRA). Ph.D., Cranfield (U.K.), 1998. BL.

Sambo, Boukary Hama. Inheritance of seedweathering resistance in sorghum [Niger]. Ph.D., Mississippi State U., 1999. 9930351.

\section{Anthropology}

Anderson, Kermyt Grant. Paternal care, divorce and step fathers: analyses of parental behavior by Anglo, Hispanic, and Xhosa men in Albuquerque, New Mexico and Cape Town, South Africa. Ph.D., U. of New Mexico, 1999. 9926823.

Becker, Mark S. Reconstructing prehistoric hunter-gatherer mobility patterns and the implications for the shift to sedentism: perspective from the Near East [Egypt]. Ph.D., U. of Colorado at Boulder, 1999. 992536).

Blum, Lauren Suzanne. Cultural context of vitamin A deficiency: a comparative study of two Hausa communities [Niger]. Ph.D., U. of Connecticut, 1999. 9926232.

Brockington, D. Land loss and livelihoods: the effects of eviction on pastoralists moved from game reserve, Tanzania. Ph.D., London, U. Coll. (U.K.), 1998.

Chapman, Rachel Rebekah. Prenatal care and the politics of protection: An ethnography of pregnancy and medical pluralism in January/March 200() 